\title{
SCREENING OF ADVANCED AROMATIC RICE LINES USING MORPHOLOGICAL AND PHYSICO-CHEMICAL CHARACTERISTICS
}

\author{
S. Paul ${ }^{1}$, P.K. Biswas ${ }^{2}$, M.S. Islam ${ }^{2}$,S.S. Siddique ${ }^{3}$, B.J. Shirazy ${ }^{3}$ and M.S. Kobir ${ }^{3}$ \\ ${ }^{1}$ Ex-MS Student, SAU \& S.O., BARI, RARS, Jashore; ${ }^{2}$ Professor, Dept. of Agronomy, SAU; \\ ${ }^{3}$ Scientist, BARI, RARS, Jashore \\ Corresponding E-mail: suchanapaul.sau@gmail.com
}

(Received: 12 January 2020, Accepted: 25 February 2020)

Keywords: Aromatic rice, morphological, physic-chemical characteristics, yield

\begin{abstract}
Short-statured and lodging resistant rice plants with long to medium slender grain are the expected criteria for aromatic rice. However, most of the aromatic rice varieties in Bangladesh do not meet the expected criteria. Therefore, this study was undertaken to detect short-statured rice plants with aromatic and long to medium slender grain where twelve advanced rice lines (derived from the local rice germplasm) with a local check Kataribhog were evaluated. All the genotypes demonstrated significant variation for different parameters such as plant height at harvest, yield per hectare, grain length, grain size, grain shape, and aroma. At harvest, the shortest plant height was obtained from SAU ADL11 $(107.09 \mathrm{~cm})$, and it was statistically similar to SAU ADL4 $(111.68 \mathrm{~cm})$ and SAU ADL5 $(111.89 \mathrm{~cm})$. However, the plant height of check variety Kataribhog was $167.17 \mathrm{~cm}$. The highest grain yield per hectare was found in SAU ADL5 (4.79 tha ${ }^{-1}$ ), where it was 2.71 tha $^{-1}$ in Kataribhog. Besides, the grain yield of shorter genotypes SAU ADL4 and SAU ADL11 was $3.47 \mathrm{tha}^{-1}$ and $3.84 \mathrm{t} \mathrm{ha}^{-1}$, respectively. The SAU ADL1 provided the highest kernel length $(7.31 \mathrm{~mm})$, and the lowest kernel length $(4.87 \mathrm{~mm})$ was recorded in the check. Kernel length of short-statured genotypes ranged from $7.01 \mathrm{~mm}$ to $6.57 \mathrm{~mm}$. Kernel size of all evaluated genotypes was long to medium; whereas, it was short for Kataribhog. Kernel shape of these short-statured genotypes was slender to medium. In case of aroma, SAU ADL3, SAU ADL5, SAU ADL7, SAU ADL9, SAU ADL10, and SAU ADL11 were moderately aromatic, and other genotypes were non-aromatic. However, Kataribhog was strongly aromatic. Finally, SAU ADL5 and SAU ADL11 were evaluated as important germplasms in respect of different characters such as shortstatured plant, long to medium slender grain, and aroma. These two lines could be potential inbreed aromatic rice genotypes for Bangladesh.
\end{abstract}

\section{Introduction}

Aromatic rice cultivars are a special group of rice genotypes (Aljumaili et al., 2018), characterized by their qualities like nut-like aroma, cooking, eating and/or super-fine grained (Roy et al., 2016). This group of rice is very popular throughout Asia and has gained wider acceptance in Europe, Australia, the Middle East and the United States of America (Sakthivel et al., 2009). According to Giraud (2013), the international trade market is covered by two aromatic rice varieties namely Basmati (from the Indian Subcontinent), and Jasmine rice (from Thailand) because of its' premium long grain and aroma. According to Kaul (1970), the premium grain was determined by grain length (> $6.0 \mathrm{~mm})$, and length: breadth ratio (L/B $2.5 \mathrm{~mm}$ to $3 \mathrm{~mm}$ ). Therefore, rice grains with these qualities can be defined as premium quality grain. Several authors (Krishna et al., 2018 and Louis et al., 2005) mentioned that the consumers' demand has significantly increased for quality grain aromatic rice. Therefore, research 
regarding aromatic rice development increases in different rice-growing countries to fulfill the consumers' demand.

In Bangladesh, the cultivated aromatic rice genotypes are mostly traditional or native types (Islam et al., 2018). The major drawback is that these native aromatic rice germplasms are low yielding per hectare (Islam et al., 2018). Long-statured and lodging susceptible nature were identified as the reasons behind the low yield of native cultivars (Mia et al.,2012).Moreover, most of these cultivars produced short bold to medium bold grain and could not meet the criteria of premium quality grain (Islam et al., 2013). Therefore, short-statured, quality grain aromatic rice is important to develop or evaluate. According to Khalid et al. (2010) morphological traits were considered effective in evaluation, as they were economic and feasible. Moreover, morphological traits can be easily transmitted to the next generation through conventional breeding (Islam et al., 2016). Apart from morphological traits, some other qualities such as milling, cooking, and eating can also be considered for the evaluation of aromatic rice germplasm (Juliano and Bechtel, 1985).

Bangladesh has a stock of above 8,000 rice germplasm of which nearly 100 are aromatic (Khalequezzaman et al., 2012). These traditional aromatic rice germplasm are great reservoirs of the valuable gene pool (Ahmed et al., 2016). However, many of these germplasm have already been lost from Bangladesh and some of them are still on the verge of extinction (Ahmed et al., 2010). Moreover, information regarding the characterization, genetic diversity, and quality of different local rice germplasm in Bangladesh is limited (Islam et al., 2018). Thus, it is important to conserve these germplasm. Meanwhile, it is necessary to characterize and evaluate these local rice germplasm both morphologically and physico-chemically. Therefore, in this study, twelve advanced lines (derived from the local rice germplasm of Bangladesh) were evaluated to find out short-statured, quality grained aromatic rice.

\section{Materials and Methods}

\section{Collection of seed}

Seeds of local aromatic Aman rice (grown in July to December) genotypes were preserved in the Department of Agronomy of Sher-e-Bangla Agricultural University, Sher-e-Bangla Nagar, Dhaka1207. Then, twelve advanced lines were selected from the local genotypes through various field observations by the Department of Agronomy of Sher-e-Bangla Agricultural University. The selected advance lines were named as SAU ADL (Sher-e-Bangla Agricultural University Agronomy Department Line) having chronological numerical as (i) SAU ADL1, (ii) SAU ADL2, (iii) SAU ADL3, (iv) SAU ADL4, (v) SAU ADL5, (vi) SAU ADL6, (vii) SAU ADL7, (viii) SAU ADL8, (ix) SAU ADL9, (x) SAU ADL10, (xi) SAU ADL11 and (xii) SAU ADL12. Kataribhog was collected from Bangladesh Rice Research Institute, Gazipur, Bangladesh and used as the check variety throughout the entire evaluation process.

\section{Experimental design and management practice}

The experiment was laid out in Randomized Completely Block Design (RCBD) with three replications and there were thirteen rice genotypes as treatment. Sprouted Seeds were sown in seedbed on and transplanted on the main field. The plot size was $6 \mathrm{~m}^{2}$, with spacing $25 \mathrm{~cm} \times 15 \mathrm{~cm} ; 8$ rows plot ${ }^{-1}, 20$ hills row ${ }^{-1}$, and one seedling hill ${ }^{-1}$. The experimental area was fertilized with $120,80,80$ and $20 \mathrm{~kg} \mathrm{ha}^{-1}$ of $\mathrm{N}, \mathrm{P}_{2} \mathrm{O}_{5}, \mathrm{~K}_{2} \mathrm{O}$ and $\mathrm{S}$ applied in the form of urea, triple super phosphate (TSP), muriate of potash $(\mathrm{MoP})$ and gypsum respectively. The entire amounts of TSP, MP, and gypsum were applied as basal dose at final land preparation. The urea was top-dressed in three equal installments. All the plots were irrigated depending on rainfall to maintain the flood condition. All the plots were dried 7 days before harvesting. 


\section{Evaluation of plant growth and yield contributing characters}

The crop was considered mature after 80 percent grain became yellow color. Harvesting was started manually at 106 days and continued up to 138 days according to the maturity of the individual lines. Ten hills were selected randomly per plot for evaluation of different growth parameters such as plant height $(\mathrm{cm})$ at harvest, the number of tillers hill $^{-1}$ at harvest, effective tillers hill ${ }^{-1}$, panicle length (basal node of the rachis to apex), total grains panicle ${ }^{-1}$, thousand grain weight (g). To determine the fertile spikelet per panicle (\%), 10 panicles were harvested at maturity from five randomly chosen plants in each of the plot. The number of filled, unfilled and total grain was also counted to compute fertile spikelet percentage panicle ${ }^{-1}$ as Kumar (2016).

$$
\text { Fertile spikelet panicle }^{-1}(\%)=\frac{\text { No.of filled grains in the panicle }}{\text { Total no.of grains in the panicle }} \times 100
$$

\section{Yield determination}

To determine the yield per plot, the $3 \mathrm{~m}^{2}$ area (from the middle portion of each plot) was separately harvested and bundled, properly tagged, and then brought to the threshing floor for recording grain and straw yield. Threshing was done using pedal thresher. Both grain and straw were sun-dried immediately after harvesting. The harvested grain was cleaned and sun-dried to a moisture content of $14 \%$ (measured by grain moisture meter). Finally, grain and straw yields per plot were determined and converted to ton per hectare $\left(\mathrm{t} \mathrm{ha}^{-1}\right)$. Then Biological yield was calculated following the formula (Youshida, 1981):

Biological yield $\left(\mathrm{t} \mathrm{ha}^{-1}\right)$ or total dry weight $\left(\mathrm{t} \mathrm{ha}^{-1}\right)=$ Grain yield $\left(\mathrm{t} \mathrm{ha}^{-1}\right)+$ Straw yield $\left(\mathrm{t} \mathrm{ha}^{-1}\right)$

The harvest index was determined according to Gardner et al. (1985) and the formula was,

$$
\text { Harvest index }(\%)=\frac{\text { Grain yield }}{\text { Biological yield }} \times 100
$$

\section{Grain quality parameters assessment}

Milling recovery: A hundred gram sample of dried (14\% moisture) paddy grain samples i. e. rough rice were dehulled to produce brown rice in a Satake Laboratory Sheller. The brown rice was milled in McGill mill number 2 (Adair, 1952). The total milled rice was calculated with the following formula (Khushet al., 1979).

$$
\text { Total milled rice }(\%)=\frac{\text { Weight of milled rice }}{\text { Weight of rough rice or paddy sample }} \times 100
$$

Head rice recovery: The broken grains were separated from the whole grains by using a grain grader and the rice kernel length greater or equal to three quarters was also considered as whole kernel.The percentage of the head rice recovery was calculated using the following equation:

$$
\text { Head rice recovery }=\frac{\text { Weight of head rice }}{\text { Weight of paddy sample }} \times 100
$$

Grain Classification: Ten de-husked entire brown rice grains were measured using digital slide calipers and based on the L/B ratio, size and shape were classified according to Table 1 and Table 2 .

Table 1. Classification of grain size

\begin{tabular}{ccc}
\hline Scale & Size Category & Length $(\mathrm{mm})$ \\
\hline 1 & Very long & More than 7.50 \\
3 & Long & 6.61 to 7.50 \\
5 & Medium or intermediate & 5.51 to 6.60
\end{tabular}


Source. Cruz and Khush (2000) and IRRI standards

Table2. Classification of grain shape

\begin{tabular}{ccc}
\hline Scale & Shape & L/B ratio $(\mathrm{mm})$ \\
\hline 1 & Slender & Over 3.0 \\
5 & Medium & 2.1 to 3.0 \\
9 & Bold & 2.0 or less than 2.0 \\
\hline
\end{tabular}

Source. Cruz and Khush (2000) and IRRI standards

Kernel length after cooking: Kernel length after cooking (KLAC) was measured according to Bhonsle and Krishnan (2010). Rice samples were cooked in a water bath for 20 min, followed by ten selected (intact at both ends) cooked rice placing on blotting paper. Finally, the length of the kernels was measured using graph paper for computing the KLAC.

Aroma content: The aroma content of all rice germplasm was evaluated according to IRRI (1971). One gram of freshly harvested milled rice was mixed with $20 \mathrm{ml}$ of distilled water and placed into a centrifuge tube $(50 \mathrm{ml}$ round bottom). The tubes were then covered with aluminum foil. The samples were placed in a boiling water bath for 10 minutes. The cooked samples were allowed to cool and the presence of aroma was smelled by a panel of experts to score as strongly aromatic, moderately aromatic, slightly aromatic and non-aromatic. A strongly scented genotype (Kalizira) was used as a check for comparison.

Statistical analysis: All the data were analyzed using the R program for statistical analysis. The means were separated using the least significant difference (LSD) test at the 0.05 level.

\section{Results and Discussion}

This investigation successfully evaluated the growth, yield contributing characters, yield and physicochemical quality of different native aromatic Aman (growing season July to December) rice genotypes.

\section{Morphological characteristics}

Plant height: Plant height is an important morphological parameter as this positively correlated to lodging (Navadiet al., 2006). Additionally, lodging disturbs the ripening process, decreases crop yield, and causes poor grain quality (Kono, 1995). The plant height at harvest for all genotypes ranged from $219.08 \mathrm{~cm}$ to $107.09 \mathrm{~cm}$ and the genotypes differed significantly (Table 3). This result was supported by Hossain et al.(2008) stated that the popular aromatic rice cultivars in Bangladesh were local with long-statured in nature and very much prone to lodging. SAU ADL11 produced the shortest plant $(107.09 \mathrm{~cm})$ which was statistically similar to SAU ADL4 $(111.68 \mathrm{~cm})$, SAU ADL5 $(111.89 \mathrm{~cm})$ and did not lodge during the maturity stage. The highest plant height was obtained from SAU ADL10 $(219.08 \mathrm{~cm})$ where Kataribhog the popular aromatic rice cultivar provided the third highest plant height $(167.17 \mathrm{~cm})$ which was statistically similar with SAU ADL2 $(159.57 \mathrm{~cm})$, SAU ADL3 $(173.26 \mathrm{~cm})$ and these long-statured plant demonstrated lodging. This result indicated that the lodging of rice plants is highly associated with plant stature and short-statured genotypes could be useful for the lodging resistant genotypes. Previously Okuno et al. (2014) also recorded that the short height rice genotypes are resistant to lodging.

Total tiller numbers hill ${ }^{-1}$ : Tillering is a vital determinant of panicle production as well as yield in rice (Miller et al., 1991). The current study found that the total tillers hill ${ }^{-1}$ at the harvesting stage varied among the evaluated genotypes. The highest total tiller numbers hill ${ }^{-1}$ at harvest was observed in the local aromatic rice genotype SAU ADL10 (18.75) followed by SAU ADL5 (15.58). The total tiller numbers hill $^{-1}$ of SAU ADL1, SAU ADL3, SAU ADL4, SAU ADL6, SAU ADL8, SAU ADL11 and 
Kataribhog were statistically similar with SAU ADL5. The minimum tiller numbers hill ${ }^{-1}$ (6.58) was obtained from SAU ADL12 (Table 3).

Table 3. Morphological characters such as plant height and total number of tillers hill ${ }^{-1}$ at harvest, and days to maturity of evaluated rice genotypes

\begin{tabular}{lccc}
\hline \multicolumn{1}{c}{ Genotypes } & $\begin{array}{c}\text { Plant height } \\
\text { (cm) }\end{array}$ & $\begin{array}{c}\text { Total tillers hill } \\
\text { (no.) }\end{array}$ & $\begin{array}{c}\text { Maturity duration } \\
\text { (days) }\end{array}$ \\
\hline SAU ADL1 & $124.16 \mathrm{e}$ & $15.36 \mathrm{~b}$ & $134.67 \mathrm{c}$ \\
SAU ADL2 & $159.57 \mathrm{~d}$ & $11.83 \mathrm{de}$ & $124.67 \mathrm{~g}$ \\
SAU ADL3 & $173.26 \mathrm{c}$ & $14.50 \mathrm{bc}$ & $126.33 \mathrm{f}$ \\
SAU ADL4 & $111.68 \mathrm{fg}$ & $14.00 \mathrm{bcd}$ & $131.00 \mathrm{e}$ \\
SAU ADL5 & $111.89 \mathrm{fg}$ & $15.58 \mathrm{~b}$ & $131.00 \mathrm{e}$ \\
SAU ADL6 & $166.14 \mathrm{~cd}$ & $11.08 \mathrm{e}$ & $134.67 \mathrm{c}$ \\
SAU ADL7 & $119.56 \mathrm{ef}$ & $12.66 \mathrm{cde}$ & $135.67 \mathrm{~b}$ \\
SAU ADL8 & $119.73 \mathrm{ef}$ & $13.17 \mathrm{bcdee}$ & $135.67 \mathrm{~b}$ \\
SAU ADL9 & $194.72 \mathrm{~b}$ & $11.83 \mathrm{de}$ & $133.33 \mathrm{~d}$ \\
SAU ADL10 & $219.08 \mathrm{a}$ & $18.75 \mathrm{a}$ & $134.33 \mathrm{c}$ \\
SAU ADL11 & $107.09 \mathrm{~g}$ & $13.33 \mathrm{bcde}$ & $136.00 \mathrm{~b}$ \\
SAU ADL12 & $202.25 \mathrm{~b}$ & $6.58 \mathrm{f}$ & $138.67 \mathrm{a}$ \\
Kataribhog & $167.17 \mathrm{~cd}$ & $15.00 \mathrm{bc}$ & $135.67 \mathrm{~b}$ \\
\hline LSD $_{(0.05)}$ & 8.74 & 2.65 & 0.78 \\
CV (\%) & 3.41 & 11.76 & 0.35 \\
\hline
\end{tabular}

The means with the same letter in a column show an insignificant difference at the $5 \%$ level

Maturity duration:SAU ADL12 recorded the maximum days (138.67 days) for maturity, whereas the minimum days (124.67 days) was recorded in SAU ADL2. Local check Kataribhog recorded 135.67 days for maturity where short statured genotypes SAU ADL4, SAU ADL5 and SAU ADL11 recorded $131.00,131.00,136.00$ days, respectively.

The variations in tillering and days to maturity might be the varietal variation. Previously several authors (Hossain et al., 1991 and Jisan et al., 2014) also identified the difference in the genetic makeup as the reason for these variations during evaluation of different lines.

\section{Yield and yield contributing parameters}

Panicle length and fertile spikelets panicle ${ }^{-1}(\%)$ : Maximum panicle length $(32.63 \mathrm{~cm})$ was recorded in genotype SAU ADL10 followed by SAU ADL9 $(30.75 \mathrm{~cm})$ which was statistically similar to SAU ADL3 (30.67), SAU AD6 (29.62) (Table 4). A minimum panicle length of $26.33 \mathrm{~cm}$ was recorded in SAU AD7 which was statistically similar to SAU AD1, SAU AD2, SAU AD4, SAU AD11 and Kataribhog (Table 4). The highest fertile spikelets panicle ${ }^{-1}(\%)$ was found in SAU ADL2 (91.57\%) followed by Kataribhog $(83.15 \%)$. The lowest fertile spikelets panicle ${ }^{-1}(\%)$ was recorded from SAU ADL7 (27.44 \%). Short statured genotypes SAU ADL4, SAU ADL5 and SAU ADL11 had 52.02\%, $64.50 \%$ and $69.52 \%$ fertile spikelets panicle ${ }^{-1}$, respectively (Table 4).

Effective tillers hill $^{-1}$ : The number of panicles or effective tillers hill ${ }^{-1}$ is the most important component of rice yield (Shahidullahet al., 2009). The maximum effective tillers hill ${ }^{-1}$ (16.75) was recorded from the genotype SAU ADL10 (Table 4).Kataribhog also produced second highest tillers $\mathrm{m}^{-}$ 2, which was statistically similar to SAU ADL3, SAU ADL7, SAU ADL11, and SAU ADL5 (Table 4). 
On the other hand, the least effective tillers hill ${ }^{-1}$ were recorded in SAU ADL12 (5.33) which was statistically similar to SAU ADL6 (7.67). This result was similar to Hossain et al. (2005) who found variation among the evaluated native aromatic rice cultivars in case of fertile tillers hill ${ }^{-1}$ which ranged from 8.6 to 11.4 .

Thousand-grain weight: Thousand-grain weight is an important yield-determining component, which is also a genetic character least influenced by the environment (Ashraf et al., 1999). Yoshida (1981) reported that under most conditions, 1000 grains of field crop is a very stable character. The highest thousand grain weight (31.97 g) was obtained from the genotype SAU ADL4 (31.97 g) which was statistically similar to SAU ADL1 (31.03g) and SAU ADL9 (31.03 g). On the other hand, the lowest thousand grain weight $(15.03 \mathrm{~g})$ was obtained from Kataribhog. Moreover the thousand grain weight of SAU ADL11 was $21.88 \mathrm{~g}$ which was statistically similar with SAU ADL7 (Table 4). The main cause of the highest and lowest 1000-grain weight could be the long-slender grain size and short-medium grain size of genotypes respectively. The previous study found that grain size determines grain weight and affects grain quality (Jiang et al., 2015).

Grain yield and harvest index (HI): Grain yield and harvest index differed significantly among the local Aman rice germplasms (Table 4). The highest grain yield $\left(4.79\right.$ tha $\left.^{-1}\right)$ was obtained from SAU ADL5 which was statistically similar to SAU ADL2 (4.55 tha $\left.{ }^{-1}\right)$, SAU ADL3 (4.47 tha ${ }^{-1}$ ) and SAU ADL9 (4.48 tha $\left.{ }^{-1}\right)$. The lowest grain yield $\left(2.59 \mathrm{t} \mathrm{ha}^{-1}\right)$ was recorded from SAU ADL7 which was statistically similar to SAU ADL6 (2.86 tha $\left.{ }^{-1}\right)$, SAU ADL12 (2.81 tha $\left.{ }^{-1}\right)$, Kataribhog (2.71 tha $\left.{ }^{-1}\right)$. However, Hossain et al. (2005) observed $3.3 \mathrm{t} \mathrm{ha}^{-1}$ yield in Kataribhog and Hoque et al. (2013) found $2.63 \mathrm{t} \mathrm{ha}^{-1}$ yield in Kataribhog. The reasons behind this yield could be the result of number of effective tillers hill ${ }^{-1}$, fertile spikelets panicle ${ }^{-1}(\%)$ and 1000 -grain weight $(\mathrm{g})$. This result was also in agreement with Hassan et al. (2003) who stated that grain yield is a function of the interplay of various yield components such as the number of productive tillers, fertility percentage panicle ${ }^{-1}$ and 1000-grain weight.

Table 4. Yield and yield contributing characters of evaluated rice genotypes after harvest

\begin{tabular}{ccccccc}
\hline Genotypes & $\begin{array}{c}\text { Panicle length } \\
(\mathrm{cm})\end{array}$ & $\begin{array}{c}\text { Fertilespikelets } \\
\text { panicle }^{-1}(\%)\end{array}$ & $\begin{array}{c}\text { Effective } \\
\text { tillers } \\
\text { hill }^{-1}(\mathrm{no} .)\end{array}$ & $\begin{array}{c}1000 \text {-grain } \\
\text { weight }(\mathrm{g})\end{array}$ & $\begin{array}{c}\text { Grain yield } \\
\left(\text { tha }^{-1}\right)\end{array}$ & $\begin{array}{c}\text { Harvest } \\
\text { index }(\%)\end{array}$ \\
\hline SAU ADL1 & $26.79 \mathrm{f}$ & $43.34 \mathrm{~g}$ & $12.69 \mathrm{bc}$ & $31.03 \mathrm{ab}$ & $3.50 \mathrm{cde}$ & $37.75 \mathrm{~b}$ \\
SAU ADL2 & $26.95 \mathrm{ef}$ & $91.57 \mathrm{a}$ & $10.50 \mathrm{de}$ & $29.96 \mathrm{bc}$ & $4.55 \mathrm{ab}$ & $43.50 \mathrm{a}$ \\
SAU ADL3 & $30.67 \mathrm{bc}$ & $50.95 \mathrm{fg}$ & $13.92 \mathrm{cbc}$ & $26.02 \mathrm{f}$ & $4.47 \mathrm{ab}$ & $20.40 \mathrm{de}$ \\
SAU ADL4 & $27.33 \mathrm{ef}$ & $52.02 \mathrm{f}$ & $12.58 \mathrm{bc}$ & $31.97 \mathrm{a}$ & $3.46 \mathrm{cde}$ & $37.17 \mathrm{~b}$ \\
SAU ADL5 & $28.27 \mathrm{de}$ & $64.50 \mathrm{~cd}$ & $14.34 \mathrm{~b}$ & $29.25 \mathrm{~cd}$ & $4.79 \mathrm{a}$ & $34.69 \mathrm{~b}$ \\
SAU ADL6 & $29.62 \mathrm{bcd}$ & $54.14 \mathrm{ef}$ & $8.42 \mathrm{f}$ & $28.97 \mathrm{~cd}$ & $2.86 \mathrm{ef}$ & $20.09 \mathrm{de}$ \\
SAU ADL7 & $26.33 \mathrm{f}$ & $27.44 \mathrm{~h}$ & $10.67 \mathrm{de}$ & $22.34 \mathrm{~g}$ & $2.59 \mathrm{f}$ & $19.18 \mathrm{de}$ \\
SAU ADL8 & $29.33 \mathrm{~cd}$ & $61.43 \mathrm{de}$ & $9.17 \mathrm{ef}$ & $28.10 \mathrm{de}$ & $3.10 \mathrm{def}$ & $36.88 \mathrm{~b}$ \\
SAU ADL9 & $30.75 \mathrm{~b}$ & $72.15 \mathrm{c}$ & $9.92 \mathrm{ef}$ & $31.03 \mathrm{ab}$ & $4.48 \mathrm{ab}$ & $33.57 \mathrm{~b}$ \\
SAU ADL10 & $32.63 \mathrm{a}$ & $68.75 \mathrm{~cd}$ & $17.08 \mathrm{a}$ & $27.22 \mathrm{ef}$ & $3.92 \mathrm{bc}$ & $16.84 \mathrm{e}$ \\
SAU ADL11 & $26.39 \mathrm{f}$ & $69.52 \mathrm{c}$ & $12.08 \mathrm{~cd}$ & $21.88 \mathrm{~g}$ & $3.84 \mathrm{bcd}$ & $35.34 \mathrm{~b}$ \\
SAU ADL12 & $29.59 \mathrm{bcd}$ & $54.76 \mathrm{ef}$ & $5.33 \mathrm{~g}$ & $27.83 \mathrm{de}$ & $2.81 \mathrm{ef}$ & $23.18 \mathrm{~cd}$ \\
Kataribhog & $27.47 \mathrm{ef}$ & $83.150 \mathrm{~b}$ & $13.00 \mathrm{bc}$ & $15.17 \mathrm{~h}$ & $2.71 \mathrm{ef}$ & $27.75 \mathrm{c}$ \\
\hline LSD $(0.05)$ & 1.37 & 8.02 & 1.88 & 1.68 & 0.81 & 5.05 \\
CV (\%) & 2.84 & 7.8 & 9.7 & 3.68 & 13.20 & 10.07 \\
\hline
\end{tabular}

The means with the same letter in a column show an insignificant difference at the $5 \%$ level 
According to Youshida (1981), the harvest index of traditional tall varieties is about $30 \%$ and for improved short varieties it is $50 \%$ and the identified reason is that dry mater partitioning to economic part is higher in short-statured varieties than the traditional one. The highest harvest index was found from the genotype SAU DL2 $(43.50 \%)$. The lowest harvest index $(16.84 \%)$ was found from SAU ADL10 which was statistically similar to SAU ADL6, SAU DL7, and SAU ADL3. Harvest Index of local cultivar Kataribhog was $27.75 \%$, where HI of short-statured genotypes SAU ADL4, SAU ADL5 and SAU ADL11 was $37.63 \%, 35.57 \%$, and $35.34 \%$ respectively.

\section{Physico-chemical parameters}

Physical properties include kernel size, shape, milling recovery, degree of milling and grain appearance (Cruz and Khush, 2000) and physico-chemical properties include cooking and eating quality like Kernel length after cooking, aroma (Rebeiraet al., 2014).

Milling Recovery (MR) (\%) and Head Rice Recovery (HRR) (\%): Milling yield is an important physical property of rice especially for market value (Rosniyana et al., 2006). A variety should possess a high turn-out of whole-grain (head) rice and total milled rice (Webb, 1985). This criterion is important because it expresses the actual yield of a consumable product. The typical range of milling recovery was from 68 to 72 percent (Hardke and Siebenmorgen, 2012). The highest MR (75.92\%) (Figure 1A) and HRR (68.64\%) (Figure 1B) were recorded in Kataribhog. Both MR (74.41\%) and HRR $(65.71 \%)$ of SAU ADL11 were statistically similar to Kataribhog. The lowest MR $(48.82 \%)$ and HRR (35.51\%) were recorded from SAU ADL7. Short-statured genotypes SAU ADL4 and SAU ADL5 had 69.19\% and 70.36\% milling recovery, respectively. Besides short stature genotypes SAU ADL4 and SAU ADL5 showed 58.94\% and 58.41\% of HRR, respectively. The MR\% of rest genotypes lays $65.24 \%$ to $74.41 \%$. Ahmed et al. (2016) also assessed agro-morphological, physico-chemical and molecular characters of rice germplasm in Bangladesh and found $65.3 \%$ to $69.9 \%$ milling rate. This study was also similar to Hossain et al.(2008) who evaluated several local aromatic rice genotypes and reported $67.3 \%$ and $67.8 \%$ HRR in Kataribhog (Philippine) and Kataribhog (deshi), respectively. The reason for this variation could be the result of different grain size and shape, moreover its a varietals characteristic (Ferdouset al., 2004).

A

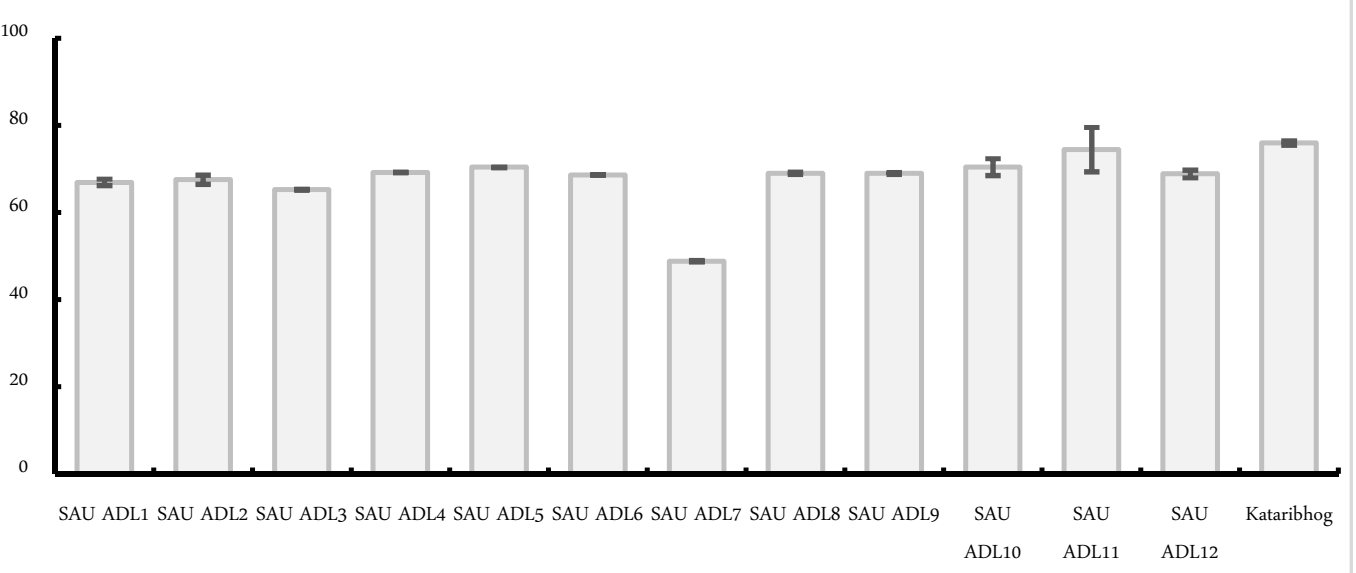




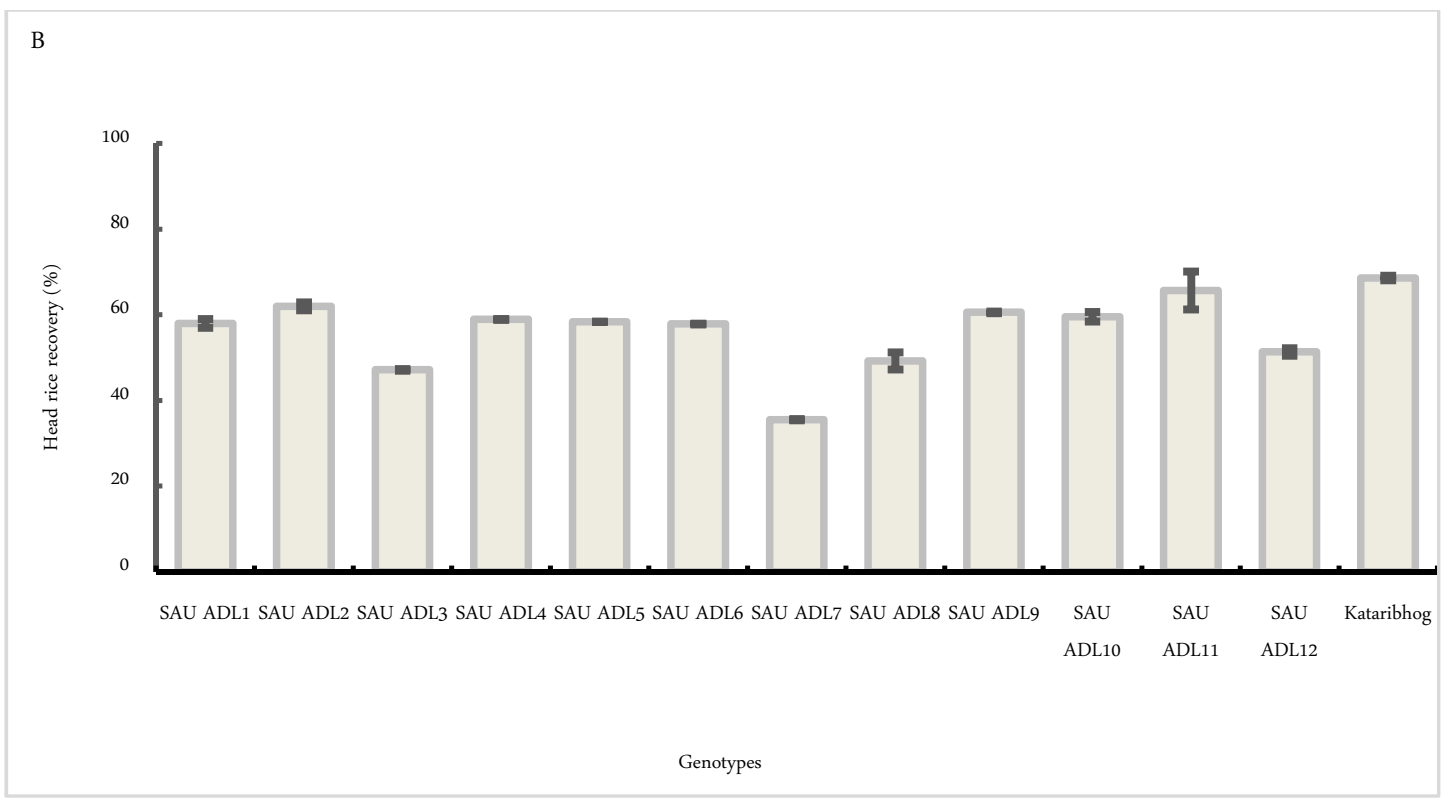

Fig. 1. Milling recovery (\%) and head rice recovery (\%) of evaluated local Aman rice genotypes. A) Millingrecovery (\%)of evaluated local Aman rice genotypes. B) Head rice recovery (\%) of evaluated local Amanrice genotypes. Vertical bars mention the $\operatorname{LSD}_{(0.05)}$ values.

Kernel length ( $\mathbf{m m})$ and breath $(\mathbf{m m})$ : Grain size and shape are the first criteria of rice quality that breeders consider in developing new varieties for release for commercial production (Adair et al., 1966). Aromatic variety with kernel length $6.0 \mathrm{~mm}$ and above is considered a widely acceptable size (Kaul, 1970). The highest kernel length $(7.31 \mathrm{~mm})$ was obtained from SAU ADL1 followed by SAU ADL9 $(7.22 \mathrm{~mm})$ (Table 5). Meanwhile, the highest kernel breadth $(2.62 \mathrm{~mm})$ was obtained from SAU ADL2. The lowest kernel length $(4.87 \mathrm{~mm})$ and breadth $(1.8 \mathrm{~mm})$ was obtained from Kataribhog. Kernel length of short statured genotypes SAU ADL4, SAU ADL5, and SAU ADL11 was 7.01mm, $6.78 \mathrm{~mm}$, and $6.57 \mathrm{~mm}$ respectively. In this investigation, the kernel length of all evaluated local germplasm was more than $6 \mathrm{~mm}$ and considered to be premium quality. However, Kataribhog does not meet the acceptable range. Islam et al. (2016) also reported medium bold scented grain in Kataribhog and that was similar to the study.

Kernel size and shape:Furthermore, the L/B ratio formulates the grain shape and the length and breadth ratio of all studied genotypes was also between the acceptable ranges $2.5 \mathrm{~mm}$ to $3 \mathrm{~mm}$ (Kaul, 1970). Kernel length and breadth ratio of all the genotypes ranged from $3.77 \mathrm{~mm}$ to $2.37 \mathrm{~mm}$ (Table 5). The highest ratio (3.77) was obtained from SAU ADL8 followed by SAU ADL7, SAU ADL3, SAU ADL10 and SAU ADL1. However, the lowest ratio (2.37) was obtained from SAU ADL2.

The kernel size of SAU ADL1, SAU ADL3, SAU ADL4, SAU ADL7, SAU ADL8 and SAU ADL10 were long and slender; SAU ADL5 was long medium; SAU ADL6, SAU ADL9 and SAU ADL11 were medium slender and SAU ADL2 and SAU ADL12 were of medium type. On the other hand the kernel size of the check variety (Kataribhog) was of short medium type. The result was similar to Hossain et al. (2008) who reported $5.2 \mathrm{~mm}$ kernel length and 2.3 length-breadth ratios in Kataribhog (Philippines) and also $4.90 \mathrm{~mm}$ grain length and 2.5 length-breadth ratios in Kataribhog (Deshi). However, the result was not supported by Dutta et al. (1998) who analyzed seven aromatic rice and reported $5.97 \mathrm{~mm}$ kernel length and 3.09 length-breadth ratio in Kataribhog.

Table 5. Physico-chemical characteristics and aroma content of evaluated genotypes 


\begin{tabular}{|c|c|c|c|c|c|c|c|}
\hline Treatments & $\begin{array}{l}\text { Kernel } \\
\text { length } \\
(\mathrm{mm})\end{array}$ & $\begin{array}{l}\text { Kernel } \\
\text { size }\end{array}$ & $\begin{array}{c}\text { Kernel } \\
\text { breadth } \\
(\mathrm{mm})\end{array}$ & $\mathrm{L} / \mathrm{B}$ ratio & $\begin{array}{l}\text { Kernel } \\
\text { shape }\end{array}$ & $\begin{array}{l}\text { Kernel length } \\
\text { after cooking } \\
(\mathrm{mm})\end{array}$ & Aroma content \\
\hline SAU ADL1 & $7.31 \mathrm{a}$ & Long & $2.23 \mathrm{de}$ & $3.28 \mathrm{bcd}$ & Slender & $9.34 \mathrm{~b}$ & non-aromatic \\
\hline SAU ADL2 & $6.27 \mathrm{~h}$ & Medium & $2.62 \mathrm{a}$ & $2.37 \mathrm{~h}$ & Medium & $8.11 \mathrm{f}$ & non-aromatic \\
\hline SAU ADL3 & $7.13 \mathrm{abcd}$ & Long & $2.10 \mathrm{f}$ & $3.40 \mathrm{~b}$ & Slender & $9.20 \mathrm{bc}$ & $\begin{array}{c}\text { moderately } \\
\text { aromatic }\end{array}$ \\
\hline SAU ADL4 & $7.01 \mathrm{bcde}$ & Long & $2.25 \mathrm{de}$ & $3.13 \mathrm{~cd}$ & Slender & $8.91 \mathrm{~cd}$ & non-aromatic \\
\hline SAU ADL5 & $6.78 \mathrm{efg}$ & Long & $2.33 \mathrm{~cd}$ & $2.92 \mathrm{ef}$ & Medium & $9.99 \mathrm{a}$ & $\begin{array}{c}\text { moderately } \\
\text { aromatic }\end{array}$ \\
\hline SAU ADL6 & 6.93 cde & Long & $2.43 \mathrm{bc}$ & $2.86 \mathrm{fg}$ & Medium & $9.13 \mathrm{bcd}$ & non-aromatic \\
\hline SAU ADL7 & $6.62 \mathrm{fg}$ & Long & $1.93 \mathrm{~g}$ & $3.43 \mathrm{~b}$ & Slender & $8.00 \mathrm{f}$ & $\begin{array}{l}\text { moderately } \\
\text { aromatic }\end{array}$ \\
\hline SAU ADL8 & $7.19 \mathrm{abc}$ & Long & $1.93 \mathrm{~g}$ & $3.77 \mathrm{a}$ & Slender & $8.99 \mathrm{bcd}$ & non-aromatic \\
\hline SAU ADL9 & $7.22 \mathrm{ab}$ & Long & $2.52 \mathrm{ab}$ & $2.88 \mathrm{fg}$ & Medium & $9.19 \mathrm{bc}$ & $\begin{array}{c}\text { moderately } \\
\text { aromatic }\end{array}$ \\
\hline SAU ADL10 & $6.89 \mathrm{def}$ & Long & $2.09 \mathrm{f}$ & $3.30 \mathrm{bc}$ & Slender & $9.03 \mathrm{bcd}$ & $\begin{array}{c}\text { moderately } \\
\text { aromatic }\end{array}$ \\
\hline SAU ADL11 & $6.57 \mathrm{~g}$ & Medium & $2.13 \mathrm{ef}$ & $3.08 \mathrm{de}$ & Slender & $8.53 \mathrm{e}$ & $\begin{array}{c}\text { moderately } \\
\text { aromatic }\end{array}$ \\
\hline SAU ADL12 & $6.60 \mathrm{~g}$ & Medium & $2.33 \mathrm{~cd}$ & $2.87 \mathrm{fg}$ & Medium & $8.78 \mathrm{de}$ & Slightly aromatic \\
\hline Kataribhog & $4.87 \mathrm{i}$ & Short & $1.80 \mathrm{~h}$ & $2.70 \mathrm{~g}$ & Medium & $6.77 \mathrm{~g}$ & Strongly aromatic \\
\hline $\begin{array}{l}\text { Acceptable } \\
\text { range }\end{array}$ & $>6 \mathrm{~mm}$ & - & - & $>3$ & - & - & - \\
\hline $\operatorname{LSD}_{(0.05)}$ & 0.29 & - & 0.13 & 0.20 & - & 0.38 & - \\
\hline $\mathrm{CV}(\%)$ & 2.53 & - & 3.39 & 3.82 & - & 2.54 & - \\
\hline
\end{tabular}

The means with the same letter in a column show an insignificant difference at the $5 \%$ level

Kernel length after cooking (KLAC): Results revealed that KLAC of screened rice ranged from 8 $\mathrm{mm}$ to $9.99 \mathrm{~mm}$ (Table 5). The highest KLAC $(9.99 \mathrm{~mm})$ was found in SAU ADL5 and the lowest KLAC $(6.77 \mathrm{~mm})$ was found in Kataribhog.

Aroma: Aroma varied among the varieties (Table 5). Among the genotypes SAU ADL3, SAU ADL5, SAU ADL7, SAU ADL9, SAU ADL10, SAU ADL11 were moderately aromatic. SAU ADL12 was slightly aromatic. SAU ADL1, SAU ADL2, SAU ADL4, SAU ADL8 were non-aromatic. The check Kataribhog was strongly aromatic.Islam et al.(2018) also found variability among 113 aromatic rice germplasms of Bangladesh and reported that more than $58 \%$ of the germplasm were well scented, $31 \%$ germplasm were moderately scented, and $11 \%$ germplasm were non-scented. Moreover, several authors (Hossain et al., 2008 and Islam et al., 2016) evaluated local cultivars and reported moderate to the strong aroma in the evaluated aromatic rice cultivars.

\section{Conclusion}

The short-statured lodging resistant aromatic rice genotypes SAU ADL5 and SAU ADL11 along with the quality grain and higher yield can be evaluated at different Agro-ecological zone of Bangladesh to promote as improved genotypes for cultivation. Other genotypes could be preserved as improved breeding materials.

\section{References}


Adair, C.R, H.M. Beachell, N.E. Jodon, T.H. Johnston, J.R. Thysell, V.E. Jr. Green, B.D. Webb and J.G. Atkins.1966. Rice breeding and testing methods in the US. In: US Dept. of Agric. Rice in the US: Varieties and production. USDA Agr. Res. Sew. Handbook.289: 19-64.

Adair, C.R. 1952. The Mcgill miller method for determining the milling quality of small samples of rice.Rice J.55(2): 21-23.

Ahmed, M.S.U., M. Khalequzzaman, M.K. Bashar andA.K.M. Shamsuddin. 2016. Agro-morphological, physico-chemical and molecular characterization of rice germplasmwith similar names of Bangladesh. Rice Sci. 23(4):211-218.

Ahmed, M.S., K. Akter, M. Khalequzzaman, E.S.M.H. Rashid and M.K.Bashar.2010. Diversity analysis in boro rice (Oryza sativa L.) accessions.Bangladesh J. Agric. Res. 35(1): 29-36.

Aljumaili, S.J., M.Y. Rafii, M.A. Latif, S.Z.Sakimin, I.W.Aroluand G. Miah. 2018.Genetic diversity of aromatic rice germplasmrevealed by SSR markers. Bio. Med.Res.Int1.2018:1-11.

Ashraf, A, A. Khalid and K. Ali. 1999.Effect of seedling age and density on growth and yield of rice in saline soil.Pak. J. Biol. Sci.30(2): 860-862.

Ashrafuzzaman, M., M.R. Islam, M.R. Ismail, S.M. Shahidullah and M.M. Hanafi. 2009.Evaluation of six aromatic rice varieties for yield and yield contributing characters.Intl. J. Agric. Biol.11(5): 616620.

Bhonsle, S.J. and S. Krishnan. 2010. Grain quality evaluation and organoleptic analysis of aromatic rice varieties of Goa. India J. Agric. Sci. 2(3):99-107.

Cruz, N.D. and G.S. Khush. 2000.Rice grain quality evaluation procedures. In:R.K. Singh, U.S. Singh and G.S. Khush, eds., Aromatic rice. Oxford and IBH Publishing Co. Pvt. Ltd., New Delhi, Calcutta, pp.15-28.

Dutta, R.K., B.P. Lahiriandm and A.B. Mia. 1998. Characterization of some aromatic and fine rice cultivars in relation to their physico-chemical quality of grains.Indian J. Plant Physiol. 3(1): 61-64.

Ferdous, N., S.K. Biswas and K.A. Kabir. 2004.Effect of milling on physiological properties of rice. In: Proc. Seminar. Bangladsh Rice. Res. Inst.Gazipur. pp.1-5.

Gardner, F.P., R.B. Pearce and R.L. Mistechell. 1985.Physiology of Crop Plants.Iowa State Univ. Press, Powa.p.66.

Giraud, G. 2013. The world market of fragrant rice, main issues and perspectives. Int. Food Agribusi.Mng. 16(2):20.

Hardke, J.T. and T. Siebenmorgen. 2012.http://www.deltafarmpress.com/rice/production-factors-affectingrice-milling-quality.

Hassan, G., N.U. Khan and Q.N. Khan. 2003.Effect of transplanting date on the yield and yield samples of rice.Rice J.55(2): 21-23.

Hoque, M., F. Yeasmin and M.M. Haque. 2013.Screening suitable aromatic rice variety for Sylhetregion of Bangladesh.BJPST.11(1): 041-044.

Hossain, M.B., M.O. Islam and M. Hasanuzzaman. 2008. Influence of different nitrogen levels on the performance of four aromatic rice varieties.Int. J. Agri. Biol. 10: 693-696.

Hossain, M.F., M.S.U. Bhuiya and M. Ahaed. 2005. Morphological and agronomic attributes of some local and modern aromatic rice varieties of Bangladesh. Asian J. Plant Sci.4: 664-666.

Hossain, S.M.A., A.B.M.M. Alam and M.A. Kashem. 1991.States of crop production technology. In: Fact searching and intervention in two FSRDP Sites Activities 1990-1991. Farming System Research and Development Programme, Bangladesh Agricultural University, Mymensingh, pp.150-154.

International Rice Research Institute. 1971. Annual Report for 1970. Los Baños, Laguna, Philippines.p.265.

Islam, M.Z., M. Khalequzzaman, M.K. Bashar, N.A. Ivy, M.M.Haque, and M.A. Mian. 2016.Variability assessment of aromatic and fine rice germplasm in Bangladesh based on quantitative traits. TheScientificWorldJ. 2796720. doi:10.1155/2016/2796720. 
Islam, M.Z., M. Khalequzzaman, M.K. Bashar, N.A. Ivy, M. Mian, B.R. Pittendrigh, M.M. Haque andM.P. Ali. 2018. Variability assessment of aromatic rice germplasm by pheno-genomic traits and population structure analysis. Sci.Reports, 8(1): 9911. doi:10.1038/s41598-018-28001-z.

Islam, N., M.Y. Kabir, S.K.Adhikary andM.S. Jahan. 2013. Yield performance of six local aromatic rice cultivars. IOSR J. Agric. Veter. Sci. (IOSR-JAVS). 6(3): 58-62.

Jiang. H., W. Yuexing, F. Yunxia, Z. Longjun, X. Jie, Y. Haiping, S. Zhenyuan, P.Jiangjie, Z. Dong, K. Shujing, Z. Li, D. Guojun, G. Longbiao, Z. Dali, Z. Guangheng, X. Lihong, X. Guosheng, L. Jiayang and Q. Qian. 2015.A rare allele of GS2 enhances grain size and grain yield in rice. Molecular Plant.8(10): 1455-1465.

Jisan, M.T., S.K. Paul and M. Salim. 2014. Yield performance of some transplant Aman rice varieties as influenced by different level of nitrogen. J. Bangladesh Agril. Univ.12: 321-24.

Juliano, B.O. and D.B. Bechtel. 1985.The grain and its gross composition. In: Rice chemistry and technology. Los Banos, Laguna: IRRI. pp.17-57.

Kaul, A.K. 1970. 'Early generation testing for quality characteristics'. II. Rice Indian J. Genet. Plant Breed.30: 237-243.

Khalequzzaman, M., M.A. Siddique and M.K. Bashar. 2012. Rice genetic resources conservation and utilization in Bangladesh: in Proceedings of the National Workshop on Plant Genetic Resources for Nutritional Food Security. pp.50-60.

Khalid, M., K.N.U. Farahatullah,A. Din andM.Y. Khan. 2010. Linkage of morphological markers in brassica. Pakistan J. Bot. 42(5):2995-3000.

Khush, G.S., M. Paule and N.M. Delacruz. 1979.Grain Quality evaluation and Improvement at IRRI. In: Proceeding of workshop on chemical aspect of rice grain quality. International Rice Research Institute, Philippines, pp.21-31.

Kono, M. 1995. Physiological aspects of lodging. In: Matsuo, T., K.Kumazawa, R. Ishii, K. Ishihara, H. Hirata eds. Science of the Rice Plant, Volume 2, Physiology. Tokyo: Food and Agriculture Policy Research Center.pp.971-982.

Krishna, L., S.C. Raju, S.S. Kumar, J. Bhadru and Y.C. Mohan. 2018. Genetics of quality and yield traits using aromatic and non-aromatic genotypes through generation mean analysis in rice (Oryza sativa L.).Int.J.Curr.Microbiol.App.Sci.7(1): 2907-2914.

Kumar, V. 2016. Characterization, inheritance and allelic relationship study of gene(s) governing aroma and quality traits in rice (Oryza sativa L.).Ph.D. thesis, Indira Gandhi KrishiVishwavidyalaya, Raipur (Chhattisgarh), India, p.52.

Louis, M.T.B, J.H. Robert, J. Qingsheng, F.R. Russell and L.E.W. Daniel. 2005.A perfect marker for fragrance genotyping in rice.Molecular Breed.16:279-283.

Miller, B.C., J.E. Hill and S.R. Roberts. 1991. Plant population effects on growth and tied in water-seeded rice. Agron. J.83: 291-297.

Mia, M.A.B., M.R. Das, M. Kamruzzaman andN.M. Talukder. 2012.Biochemical traits and physicochemical attributes of aromatic-fine rice in relation to yield potential.Am. J. Plant Sci. 3: 17881795.

Navadi, A., M. Iqbal, K. Stranzke andD. Spaner. 2006. The relationship between lodging and plant height in a diverse wheat population. Can. J. PlantSci. 86(3):723-726.

Okuno, A., K. Hirano, K. Asano, W. Takase, R. Masuda, Y. Morinaka, M. Ueguchi-Tanaka, H. Kitano andM. Matsuoka. 2014. New approach to increasing rice lodging resistance and biomass yield through the use of high gibberellin producing varieties. Plos One. 9:1-12.

Rebeira, S.P., H.A.M. Wickramasinghe, W.L.G. Samarasinghe and B.D.R. Prashantha. 2014. Diversity of grain quality characteristics of traditional rice (Oryza sativa L.)varieties in Sri Lanka.Trop. Agric. Res.25(4): 570 - 578.

Rosniyana, A., M.A. Hashifah and S.A. ShariffahNorin. 2006. Quality evaluation of retailed packed Malaysian milled rice sold in the market. J. Trop. Agric. Food Sc. 34(1): $45-55$. 
Roy, P.S., R. Samal, G.J.N.D. Rao, S.S.C. Patnaik, N.N. Jambhulkar, A. Patnaik and T. Mohapatra. 2016. Differentiation and description of aromatic short grain rice landraces of eastern Indian state of Odisha based on qualitative phenotypic descriptors. BMC Ecol. 16: 36.

Sakthivel, K., R.M. Sundaram, S.N. Rani, S.M. Balachandran and C.N. Neeraja. 2009. Genetic and molecular basis of fragrance in rice.Biotechnol. Adv.27:468-473.

Shahidullah, S.M., M.M. Hanafi, M. Ashrafuzzaman, M.R. Ismail and M.A. Salam. 2009.Tillering dynamics in aromatic rice genotypes.Int. J. Agric. Biol.11: 509-514.

Webb, B.D. 1985. Criteria of rice quality in United States. In: Rice chemistry and technology, Los Banos, Laguna: IRRI. pp.403-442.

Yoshida, S. 1981. Yield and Yield Components. In: Fundamentals of Rice Crop Science. IRRI, Manila, Philippines. pp.60-63. 